\title{
Biochemical, Anti Microbial and Organoleptic Studies of Spinach (Spinaciaoleracea)
}

\author{
${ }^{1}$ Dr. (Mrs.) Jyoti D. Vora, ${ }^{2}$ Ms Lakshmi Rane, ${ }^{3}$ Ms. SwethaAshokkumar \\ ${ }^{1,2,3} \mathrm{Head}$, Department of Biochemistry \& Food Science and Quality Control, RamnarainRuia College, Matunga, \\ Mumbai- 400019.
}

\begin{abstract}
:
Spinach (Spinaciaoleracea) is an edible flowering plant in the family of Amaranthaceous. It is native to central and southwestern Asia. It is an annual plant (rarely biennial), which grows to a height of up to $30 \mathrm{~cm}$. Spinach may survive over winter in temperate regions. The leaves are alternate, simple, ovate to triangular-based, very variable in size from about $2-30 \mathrm{~cm}$ long and $1-15 \mathrm{~cm}$ broad, with larger leaves at the base of the plant and small leaves higher on the flowering stem.

To substantiate this, an analysis of the proximate principles of the samples was carried out using bench science experiments. The proximate profiles of Carbohydrate, Minerals, proteins and Crude fibers were analysed. The study showed a linear increase in Proteins, Carbohydrates, Calcium, Iron, Phosphorous and Vit $C$ content. At the same time the composition of crude fibers were lowered.

Encouraging result was obtained to conclude that Spinach ishigh in all nutritional content.

Microanalysis was carried out on the extracted spinach sample after which MIC and RT-PCR was carried out. The experiment undertaken confirms the antimicrobial property of the aqueous extracts of spinach. The extract has presence of a bactericidal compound which was evident from the results obtained using Real Time PCR. Therefore aqueous extracts of spinach have an effective antimicrobial activity against severe gastrointestinal tract pathogens such as Salmonella typhi and must be studied against other pathogens as well.

Spinach has many health benefits. This plant is loaded with calcium, but very little of spinach's calcium is absorbed by the human body due to the ant nutrient oxalate content.Additionally, there is far more to bone than just calcium. Spinach provides a number of minerals that are essential for strong and healthy bones. These include magnesium, copper, manganese, phosphorus and, particularly zinc. Zinc works synergistically with calcium to "mineralize" calcium into bone.

The commercial appeal of spinach was also speculated using value for money (VFM) studies.
\end{abstract}

Keywords: Amaranthaceous, micro-analysis, salmonella typhi, proximate principles, value for money

\section{Introduction:}

Spinach (Spinaciaoleracea) is an edible flowering plant in the family of Amaranthaceous. It is native to central and southwestern Asia. It is an annual plant (rarely biennial), which grows to a height of up to $30 \mathrm{~cm}$. Spinach may survive over winter in temperate regions. The leaves are alternate, simple, ovate to triangular-based, very variable in size from about $2-30 \mathrm{~cm}$ long and $1-15 \mathrm{~cm}$ broad, with larger leaves at the base of the plant and small leaves higher on the flowering stem. The flowers are inconspicuous, yellow-green, 3-4 mm diameter, maturing into a small, hard, dry, lumpy fruit cluster $5-10 \mathrm{~mm}$ across containing several seeds.Spinach is sold loose, bunched, packaged fresh in bags, canned, or frozen.Spinach has a high nuitritional value and is extremely rich in antioxidants, especially

When fresh, steamed, or quickly boiled. It is a rich source of vitamin A( and especially high in lutein), vitamin $\mathrm{C}$, vitamin $\mathrm{E}$, vitamin $\mathrm{K}$, magnesium, manganese, folate, betaine, iron, vitamin $\mathrm{B}$ 2, calcium, potassium, vitamin B6, folic acid, copper, protein, phosphorus, zinc, niacin, selenium and omega-3 fatty acids.

Recently, opioid peptides called rubiscolins have also been found in spinach.

Polyglutamyl folate (vitamin B9 or folic acid) is a vital constituent of cells, and spinach is a good source of folic acid. Boiling spinach can more than halve the level of folate left in spinach, but microwaving does not affect folate content. Vitamin B9 was first isolated from spinach in 1941.

\section{Aims and objectives:}

The aims and objectives of this project are as follows:

* To study the nutritional profile of Spinaciaoleracea.

* To explore the health benefits.

* To understand the biochemical, antibacterial, and genomic aspects.

* To carry out sensory evaluation using spinach containing recipe in order to underline the sociocultural and organoleptic acceptance of spinach. 
* To quantitatively analyse the sensory evaluation data using standard biostatistical operations. Significance of research:

$\checkmark \quad$ Spinaciaoleracea (commonly known as Spinach) is an enormously popular green vegetable. Spinach is well known for its availability of iron which is a vital nutrient for the body. Apart from iron, spinach is also considered a rich source of vitamin A, C, E, and K, magnesium, calcium, potassium, folic acid, zinc, phosphorous, and few other minerals. It is also a good source of proteins and omega-3-fatty acids.

$\checkmark$ Spinach leaves are demulcent or soothing agents, refrigerant or coolants, diuretic and milk laxative. Due to these properties of spinach they have many health benefits. It helps with constipation, anemia, acidosis, night blindness, tooth disorders and many other health issues. It can be safely given in case of cystitis, nephritis and scanty urination due to dehydration.

$\checkmark \quad$ I therefore feel that we all can benefit from further research into these health benefits and how they impact a human being's diet can be explored further.

\section{Plan of work:}

Analyses of Spinaciaoleracea (spinach) for proximate principles like carbohydrates, proteins, minerals, crude fibers were performed using standard biochemical methods. Sensory evaluation was also carried out to analyze the acceptance of food containing spinach.

Selection of sample:

Freshly prepared spinach sample was used for the testing of proximate principles

Parameters considered for analysis:

The following parameters were analyzed for the selected sample:

1. Estimation of carbohydrates by Anthrone method

2. Estimation of proteins by Folin Lowry method

3. Estimation of crude fiber

4. Estimation of calcium by EDTA

5. Estimation of iron by Wong's method

6. Estimation of phosphorous by Fiske-Subbarow method

7. Estimation of vitamin C Iodometrically

Sensory Evaluation:

A questionnaire was prepared and given to a panel of 56 semi-trained members. The initial part of the evaluation was non invasion and latter part was invasive which includes the tasting of the samples. The 2 samples were served to the panel members and the samples where; sample A as sweet corn and spinach sandwich and sample B as sweet corn sandwich.

\section{Results:}

The results of the proximate principles were as follows:

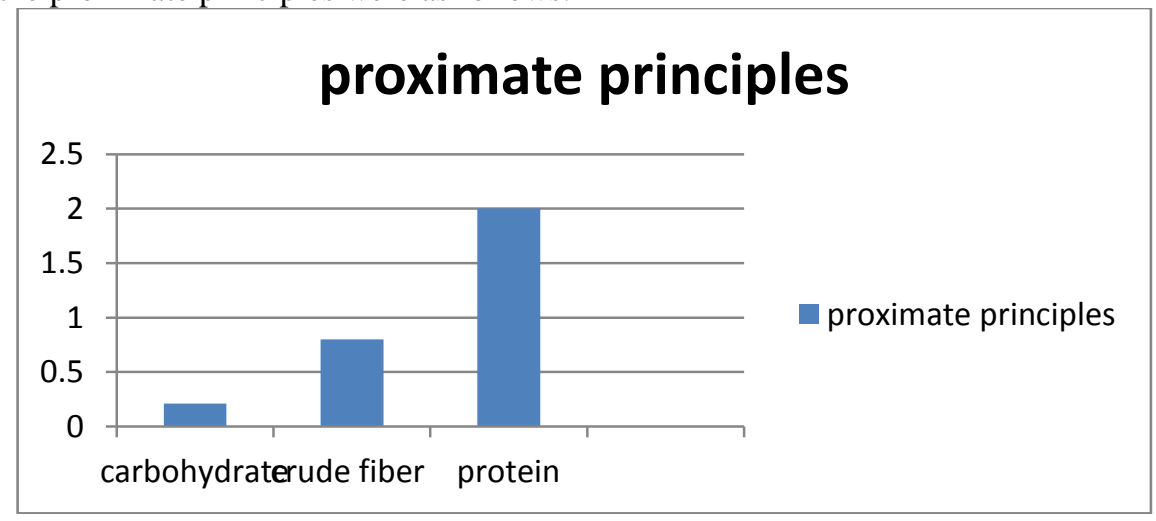

The results of mineral analysis were as follows: 


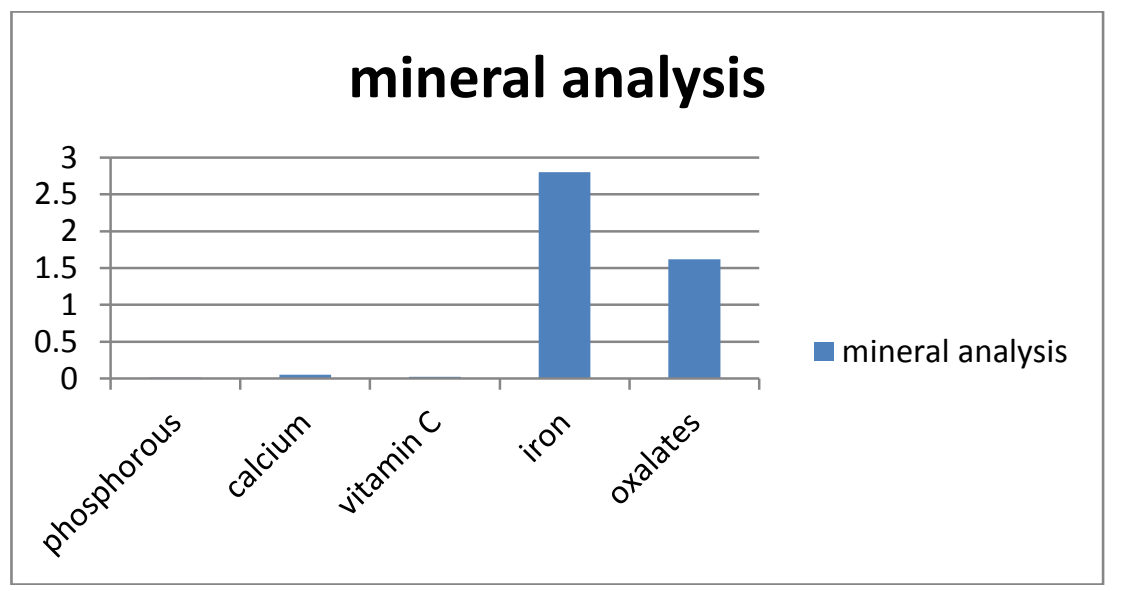

\section{Conclusion:}

$\checkmark$ proximate principles of the samples was carried out using bench science experiments

$\checkmark$ The proximate profiles of Carbohydrate, Minerals, proteins and Crude fibers were analysed

$\checkmark$ The study showed a linear increase in Proteins, Carbohydrates, Calcium, Iron, Phosphorous and Vit C content

$\checkmark \quad$ At the same time the composition of crude fibers were lowered

$\checkmark$ Encouraging result was obtained to conclude that Spinach is high in all nutritional content

$\checkmark$ After performing MIC, RT-pcr, and PCR; a bactericidal compound was found showing that there is total inhibition towards Salmonella typhi

$\checkmark$ The sensory evaluation showed that the sample with spinach was largely accepted

All objectives were met. Thus, the work can be concluded by saying that the sweet corn and spinach sandwich sample was found to be nutritive, inexpensive, and can be used as a nutraceutical which is VFM.

Future perspectives:

$\checkmark \quad$ Spinach has many health benefits

$\checkmark$ This plant is loaded with calcium, but very little of spinach's calcium is absorbed by the human body due to the ant nutrient oxalate content

$\checkmark$ Additionally, there is far more to bone than just calcium. Spinach provides a number of minerals that are essential for strong and healthy bones

$\checkmark$ These include magnesium, copper, manganese, phosphorus and, particularly zinc

$\checkmark$ Zinc works synergistically with calcium to "mineralize" calcium into bone

$\checkmark$ Aqueous extracts of spinach have an effective antimicrobial activity against severe gastro-intestinal tract pathogens such as Salmonella typhi and can be studied against other pathogens as well

$\checkmark$ Antioxidants can be studied as it has been proved to prevent strokes and also have shown to benefit the brain by improving memory and learning.

$\checkmark$ Hence further studies can be performed on these properties to enhance the knowledge of their benefits

[1]. Biochemical Methods, 2nd edition,

\section{References:}

[2]. Dr. S. sadasivam, A.Manickam,

[3]. New Age International Publication

[4]. Laboratory Manual in Biochemistry

[5]. Jayaraman J.

[6]. New Age International Publication

[7]. Laboratory manual

[8]. T.Y.BSc Biochemistry and M.Sc Biochemistry

[9]. Department of Biochemistry and Food Science and Quality Control

\section{Webliography:}

[10]. National Geographic Magazine, Vol 96:2

[11]. Douglas Harper, Online Etymological Dictionary s.v. spinach

[12]. Spinach - Natural Benefits and Curative Properties 
[13]. Spinach for bone health

[14]. Spinach for brain health

[15]. Jacques Rolland and Carol Sherman, "Spinach". The Food Encycloped

[16]. Google images

[17]. U.S. Department of Agriculture, Agricultural Research Service. 2005

[18]. Williams, Sue Rodwell; Long, Sara (1997). Nutrition and diet therapy 